\title{
Artigos
}

\section{A Oficina Sanitária Pan-americana e a cooperação internacional na educação superior de enfermeiras no Brasil: 1942-1959}

\author{
André Luiz Vieira de Campos \\ Universidade do Estado do Rio de Janeiro
}

Cooperação internacional em saúde

O tema da cooperação internacional em saúde apenas recentemente passou a merecer a atenção dos historiadores. Mesmo os estudiosos das relações internacionais - ofuscados pelos temas clássicos da diplomacia, guerra e comércio - pouco analisaram o papel da interdependência sanitária na configuração dos Estados nacionais ao inspirar métodos, técnicas e estratégias de política externa, especialmente no pós-1945. Também os estudos sobre os sistemas de bem estar social - campo tradicional de cientistas sociais - focalizam menos os aspectos internacionais do welfare do que os sistemas nacionais. Entretanto, as organizações internacionais de saúde desempenharam aspecto vital para a organização destes sistemas, estabelecendo, por exemplo, padrões de qualidade e treinamento de pessoal. ${ }^{1}$ Portanto, as organizações e a cooperação internacional em saúde são objetos que merecem maior atenção dos historiadores. $^{2}$

A cooperação internacional em saúde se originou na interseção das trocas econômicas e científicas no final do século XIX e foi impulsionada por uma rede de especialistas e agências a partir da criação da Organização de Saúde da Liga das Nações, consolidando-se após 1945, com a criação do sistema mundial da Organização das Nações Unidas (ONU). A cooperação em saúde teve suas raízes na bacteriologia e na saúde pública, no intercâmbio científico 
e na diplomacia dos Estados nacionais e vincula-se aos projetos modernizadores de governos, agências internacionais e burocracias comprometidas com ideais humanistas e de desenvolvimento. É ao mesmo tempo, diplomacia, ajuda humanitária e ao desenvolvimento, propaganda política, interesse econômico, cooperação e competição científica. Neste sentido, vai muito além dos acordos sanitários do final do século XIX, limitados às quarentenas e interdições. $^{3}$

Uma das funções das organizações internacionais de saúde é a de promover uniformização de padrões de qualidade. Desde os primeiros tratados sobre quarentena e desinfecção de navios, passando pelo controle de medicamentos e vacinas e elaboração de estatísticas vitais, as agências internacionais favoreceram, especialmente no pós-1945, a criação de padrões técnicos de produção, de educação e treinamento de profissionais. No campo específico da enfermagem no Brasil - tema deste artigo - a agência internacional pioneira neste trabalho foi, ainda na década de 1920, a Fundação Rockefeller (FR), seguida, na década de 1940, do Instituto de Assuntos Interamericanos (IAIA) que, em parceria com o Serviço Especial de Saúde Pública (SESP), desenvolveu um Programa de Enfermagem objetivando a criação de escolas; a formação de enfermeiras profissionais, auxiliares, visitadoras sanitárias; a expansão e melhoria dos serviços. ${ }^{4}$

A Organização Pan-americana da Saúde (OPAS) - originalmente Oficina Sanitária Pan-americana -, a mais antiga agência internacional de saúde ainda em funcionamento e uma das primeiras instituições de cooperação sanitária, substituiu o papel originalmente desempenhado na América Latina pela FR e pelo IAIA na cooperação em enfermagem. Nas décadas de 1940 e 1950, a Oficina Sanitária Pan-americana (doravante Oficina ou Oficina Sanitária), adotando os princípios organizacionais, científicos e de atuação no exterior da FR, promoveu, em todo o subcontinente, um amplo programa de elevação da qualidade do ensino superior de enfermagem, fundamentado nos padrões internacionais regulados pelo Conselho Internacional de Enfermeiras (CIE). ${ }^{5}$

O programa de enfermagem da Oficina teve sua origem em 1942, porém ganhou maior dimensão a partir de 1947, quando Fred Soper foi eleito diretor (1947-1957) da agência. Em 1947, a Oficina foi reformulada sob o nome de Organização Pan-americana de Saúde e associou-se à Organização Mundial 
de Saúde (OMS), transformando-se na agência regional da OMS para o continente americano. Nesta condição, a OPAS vai continuar a expandir o trabalho de cooperação em saúde da Oficina, objetivando a elevação do padrão da educação superior e dos serviços de enfermagem, ampliando, para isto, o número de escolas profissionais e de enfermeiras diplomadas no Hemisfério.

\section{A Oficina Sanitária Pan-americana e seu programa de enfermagem}

\section{ORIGENS: 1942-1947}

Na primeira metade da década de 1940, observa-se um aumento significativo de informações sobre enfermagem no Boletim da Oficina Sanitária Pan-americana (doravante BOSP ou Boletim). ${ }^{6}$ Especialmente a partir de 1943, registra-se um crescimento do volume de matérias sobre o tema, particularmente notícias relativas a um serviço de cooperação interamericano em enfermagem, com ênfase na criação de escolas profissionais de enfermeiras. Este conjunto de informações, fontes principais deste artigo, constitui um importante documento sobre a história desta profissão na América Latina e registra o surgimento de um serviço de assessoria em enfermagem da Oficina. $^{7}$

A criação de escolas profissionais, ou seja, de nível superior de acordo com os padrões internacionais do CIE, é a notícia que mais chama a atenção no Boletim neste período. Entre março de 1940 e outubro de 1944, organizaram-se doze novas escolas na América Latina, entre elas, a Escola de Enfermagem da Faculdade de Medicina de São Paulo (1943) e a Escola de Enfermagem do Estado do Rio de Janeiro (1944), em Niterói, ambas resultado da ação cooperativa do Serviço Especial de Saúde Pública. A presença de outras agências internacionais de saúde na criação de escolas de enfermagem profissional no Brasil nos indica que a Oficina não estava sozinha neste campo, mas atuava associada a uma rede integrada de agências internacionais. ${ }^{8}$

Devemos entender as origens do programa de enfermagem da Oficina Sanitária na conjuntura da Segunda Guerra Mundial, quando a Política de Boa Vizinhança determinou a criação de programas cooperativos bilaterais. Neste contexto, destaca-se a criação do Instituto de Assuntos Interamericanos em 1940, responsável por diversos acordos sanitários com países do 
subcontinente. No Brasil, a ação do IAIA resultou na criação do Serviço Especial de Saúde Pública, responsável por uma ampla atuação na área da saúde, incluindo a enfermagem. ${ }^{9}$

Isto não significa, entretanto, que a cooperação internacional foi um movimento imposto 'de fora para dentro'. O Estado brasileiro vivia um processo de modernização que incluía medidas para ampliar a ação do poder público sobre o território. Nesta perspectiva, como apontado por diversos autores, as políticas de saúde pública significaram a criação de serviços que alcançassem as populações brasileiras em todo o território nacional. ${ }^{10}$ Como apontou Fonseca, existia um duplo movimento entre os interesses do Brasil e a agenda sanitária em debate em arenas internacionais, particularmente em "congressos e conferências patrocinadas pela Oficina Sanitária Pan-americana." 11

A Oficina realizou diversos congressos nas décadas de 1930 e 1940, procurando se consolidar enquanto fórum de interação entre os diversos países latino-americanos. Neste contexto, foram adotadas várias políticas de apoio a estes países, entre elas o fornecimento de assessoria técnica e distribuição de bolsas de estudo para a formação de profissionais nos Estados Unidos. ${ }^{12}$ Já em 1940 a Oficina concedeu, através de recursos do Instituto de Assuntos Interamericanos, da Fundação Rockefeller, do Departamento de Estado e do Serviço de Saúde Pública dos Estados Unidos, quarenta e três bolsas de estudos nos Estados Unidos para estudantes latino-americanos de medicina, engenharia sanitária e enfermagem. A parceria desdobrou-se em um projeto especifico de enfermagem em 1942, quando o IAIA e a FR ofereceram recursos à Oficina para que esta empreendesse "um ambicioso programa de ajuda para estudos e melhoramentos dos serviços de enfermagem" no Hemisfério. ${ }^{13}$ Em seu relatório daquele ano, o diretor da Oficina detalhou que este projeto implicaria na "coordenação e integração de todas as atividades de enfermagem das Repúblicas" [do continente]. ${ }^{14}$ Tendo como referência o modelo de formação de enfermeiras norte-americano, o IAIA havia avaliado que a virtual "inexistência de enfermeiras profissionais na América Latina" implicava em grave empecilho para a 'modernização' dos sistemas de saúde da região. Assim, o Instituto estabeleceu como objetivo "assegurar a uniformização de padrões de enfermagem no Hemisfério Ocidental." "15

Os interesses de grupos profissionais também devem ser considerados para que se compreenda a amplitude do tema analisado: se por um lado, a 
burocratização do Estado brasileiro implicou na profissionalização de muitas carreiras de saúde; por outro, já havia um movimento internacional para a profissionalização da enfermagem, estimulado pelo CIE e pela Oficina. Um Editorial do Boletim, em 1943, anunciava: "Não por coincidência, a Oficina Sanitária Pan-americana inicia um serviço (...) continental de enfermagem, ao mesmo tempo em que se celebra no Chile, o I Congresso Interamericano de Enfermagem." Este Congresso, bem como o novo programa da Oficina, eram indícios de que a enfermagem "deixava de ser uma devoção" e tornava-se "uma profissão (...) para a qual se leva uma vocação decidida e vários anos de estudos."

Observe-se que, ao rejeitar o termo 'devoção' e utilizar a palavra 'vocação', o Editorial indicava um afastamento da visão tradicional da enfermeira como 'irmã de caridade', reforçando a idéia da enfermagem como uma carreira profissional que, apesar de exigir 'vocação', não era confessional, mas técnico-científica. Assim, o Editorial enfatizou a necessidade de elevar a qualidade do ensino, de ampliar o número de estudantes de enfermagem e anunciou a criação, no Boletim, da seção Enfermagem "que se propõe a manter para o grupo de interessadas no desenvolvimento desta profissão no Continente." 16

A sugestão para a criação desta nova seção no Boletim partiu do I Congresso Interamericano de Enfermagem, que também recomendou: a criação de uma Revista Pan-americana de Enfermagem; a criação de escolas profissionais, incorporadas às universidades e dirigidas por enfermeiras; a criação de cursos de pós-graduação; a organização de associações nacionais, e a realização de Congressos Interamericanos bianuais. ${ }^{17}$ Estas deliberações apontavam para a agenda clássica de profissionalização: ensino superior de qualidade; regulação, organização corporativa e instrumentos de produção e circulação de saber. Percebe-se, pelo conjunto destas recomendações, que havia lideranças comprometidas com a profissionalização da enfermagem no continente. Estes interesses encontraram na Oficina e no seu programa de enfermagem, um canal de expressão e ação.

É importante registrar que o Programa de Enfermagem da Oficina não partiu de um vazio. Desde a década de 1920, refletindo os interesses dos países membros, a Oficina vinha incentivando a enfermagem em saúde pública no continente. Este fato foi enfatizado no relatório anual do diretor, de 1924: “a Argentina tem grande interesse nos serviços de visitação de enfermagem 
(...) a Bolívia (...) inaugurou sua primeira escola nacional de enfermagem (...) o Brasil desenvolveu um serviço de enfermeiras visitadoras em cooperação com a Fundação Rockefeller."18

O Brasil havia criado, em 1923, em convênio com a Fundação Rockefeller, sua primeira escola de enfermagem de padrão internacional, a Escola Ana Nery. Em 1926, as lideranças da profissão fundaram a Associação Brasileira de Enfermeiras Diplomadas (ABED), órgão que, em 1954, transformou-se na Associação Brasileira de Enfermagem (ABEN). Ainda em 1926, a Associação de enfermeiras diplomadas do Brasil foi reconhecida e afiliada ao Conselho Internacional de Enfermeiras. Em 1933, a ABED começou a publicar os Anais de Enfermagem, periódico trimestral que, em 1954, teve seu nome alterado para Revista Brasileira de Enfermagem, existente até os nossos dias. A Revista, assim como a própria criação e atuação daquelas organizações, deve ser entendida como um grande esforço de união e organização da enfermagem brasileira, dentro do seu projeto pela profissionalização. A Revista foi, ao lado da organização de congressos, um forte instrumento da ABEN para a promoção da integração destas profissionais a nível nacional e internacional, para a divulgação dos princípios e valores da enfermagem, e para a defesa de seus interesses profissionais. Assim, o programa de enfermagem da Oficina já encontrou, no Brasil, um terreno de interesses corporativos fértil para seus objetivos.

Durante os cinco anos de parceria entre a Oficina e o IAIA (1942-1947), o papel da primeira no campo da cooperação em enfermagem limitou-se a fornecer bolsas de pós-graduação nos Estados Unidos, enviar enfermeiras norte-americanas para assessorar na organização de escolas e serviços de enfermagem nas diversas repúblicas do continente, e fornecer literatura especializada às escolas. Entretanto, este período marcou a construção de uma rede que se aprofundou no período seguinte, significando a entrada definitiva da agência neste campo.

\section{O PERÍODO 1947-1959: A GESTÃO DE FRED SOPER E A INSTI- TUCIONALIZAÇÃO DO PROGRAMA DE ENFERMAGEM DA OFICINA}

O envolvimento da Oficina na cooperação em enfermagem no Hemisfério aprofundou-se em 1947, quando de sua reorganização e transformação em 
Organização Pan-americana de Saúde - OPAS. Durante a XII Conferência Sanitária Pan-americana, realizada em Caracas, em 1947, os delegados decidiram reorganizar a Oficina Sanitária Pan-americana, que foi transformada em agência de saúde para as Américas, da Organização Mundial de Saúde. A OPAS, que surgiu desta reorganização e passou a fazer parte da ONU como órgão da OMS, compreendia quatro organismos: a Conferência Sanitária Pan-americana; o Conselho Diretor; o Comitê Executivo; e a Oficina Sanitária Pan-americana, esta última, encarregada dos diversos programas médicos e sanitários. O programa de enfermagem, agora da OPAS, continuou sob a responsabilidade da Oficina Sanitária Pan-americana. Com esta reforma, a agência ganhou mais recursos, programas, pessoal e, naturalmente, mais poderes e responsabilidades. Seu orçamento passou de cerca de US\$ 522 mil em 1948 para mais de US $\$ 4$ milhões em 1954. Seu pessoal permanente, que consistia de trinta e duas pessoas em 1947, chegou a mais de 400 funcionários em 1954. ${ }^{19}$

A reforma de 1947 criou formalmente a Divisão de Enfermagem, institucionalizando o programa de enfermagem da Oficina. A Conferência de Caracas em 1947, também elegeu o médico norte-americano Fred Soper diretor da OPAS, cargo que ocupou até 1957. Foi durante sua gestão que a cooperação em enfermagem profissional da OPAS cresceu de forma vertiginosa. Soper havia sido diretor da Fundação Rockefeller no Brasil. Estava, portando, familiarizado com a tradição, as técnicas, e os procedimentos de cooperação internacional desenvolvidos pela FR no Brasil e outros países da América Latina. Foi o próprio Soper quem, na comemoração do dia internacional da saúde em 1948, anunciou:

resolvemos dar maior importância à enfermagem porque este grupo constitui um elemento indispensável no conjunto de trabalhadores empenhados em melhorar a saúde de cada país. (... ) Nossa Oficina está melhorando as condições da Divisão de Enfermagem de maneira que ela possa prestar ajuda a qualquer país que a solicite. ${ }^{20}$

De fato, a partir do início de sua gestão, encontramos informações neste sentido no Boletim da Oficina Sanitária Pan-americana. Cresceu o volume de notícias sobre enfermagem no Boletim e são formalmente organizados e financiados pela Oficina, congressos, conferências, publicações e 
pesquisas. Este período, que se estendeu até 1959, pode ser considerado o auge da cooperação em enfermagem de nível superior promovida pela OPAS no Hemisfério.

A leitura do Boletim nos fornece um bom indício da importância que as enfermeiras profissionais ganharam a partir de 1947: entre 1945 e 1965 a enfermagem foi o terceiro tema mais abordado nas páginas deste periódico. Ao contrário do período anterior, observa-se, especialmente a partir de 1949, a publicação de um grande número de artigos científicos nos mais diversos aspectos da enfermagem, evidenciando um crescimento da produção e especialização neste campo. A publicação deste grande volume de artigos refletiu-se na efetiva organização da uma editoria de Enfermagem - anunciada em 1943, mas só criada de fato em 1949 - sob a responsabilidade da enfermeira Mary Alberti da Divisão de Enfermagem da Oficina, em Washington.

Fred Soper anunciou em 1948 que o objetivo da Divisão de Enfermagem era "prestar apoio a qualquer país que o solicite". Mas qual era o propósito desta Divisão? De que forma se dava a cooperação da OPAS no campo da enfermagem? Podemos identificar três níveis privilegiados de ação: apoio à educação de nível superior através de assessoria técnica para organização e/ou reformulação de escolas dentro dos padrões do CIE; organização de seminários, congressos e encontros regionais e internacionais; e divulgação científica, através da tradução e publicação de artigos e do intercâmbio profissional. Estes três níveis de atuação convergiam, até o final da década de 1950, para a promoção da educação de nível superior. Assim, oficialmente "os objetivos da Divisão de Enfermagem da Oficina Sanitária Pan-americana consistem em estimular e promover os altos níveis de educação e serviço de enfermeiras em todo o continente americano." 21

Tendo em vista este objetivo, o primeiro passo da Divisão de Enfermagem se consistiu na avaliação de 48 escolas existentes na América Latina, sendo 13 delas no Brasil. Entre outros elementos, observaram-se seus requisitos de admissão e currículos, variáveis que foram comparadas com os padrões exigidos pelo Conselho Internacional de Enfermeiras, grande guardião do padrão Nightingale. Registre-se que estas avaliações, além de servirem de base ao programa, também representavam respostas da Oficina a diversos Estados latino-americanos, entre eles o brasileiro, empenhados em processos de modernização de seus sistemas de saúde. ${ }^{22}$ 
Outras avaliações foram realizadas em 1949 e 1952 - desta vez através de trabalhos de campo. Em 1949, das 59 escolas visitadas no Brasil, sete foram desclassificadas por não oferecerem pelo menos três anos de curso com prática clínica, um dos requisitos exigidos pelo CIE. Do total das escolas avaliadas, 25\% receberam a classificação mais alta, entre estas estavam cinco escolas no Brasil. Eram elas: Escolas de Enfermeiras Rachel Haddock Lobo (Rio de Janeiro), Escola de Enfermagem do Estado do Rio de Janeiro (Niterói), Escola de Enfermagem da Universidade de São Paulo, Escola de Enfermagem Carlos Chagas (Belo Horizonte) e Escola de Enfermagem Magalhães Barata (Belém). A Escola Ana Nery não foi mencionada nesta lista talvez porque já fosse reconhecida como 'escola padrão’ e, portanto não tivesse sido objeto de avaliação. Entre as sugestões do primeiro estudo sobressai a que recomendava investimentos nas escolas que fossem dirigidas por enfermeiras formadas, com corpo docente qualificado, o que ratifica o foco do programa na formação de nível superior e na profissionalização. ${ }^{23}$ No estudo de 1952 destacaram-se como grande ponto positivo alcançado pelo programa o avanço na educação de nível superior e a consciência da profissionalização. Segundo a assessora da Divisão de Enfermagem da Oficina, Agnes Chagas, o conceito de enfermagem profissional estava tão difundido que em "dezenove dos vinte países latino-americanos havia escolas de enfermagem com programas de três anos", conforme recomendava o CIE. Este dado mostrava, segundo a avaliadora, que "neste Hemisfério já se compreende que a enfermeira empírica está muito longe de ser uma verdadeira enfermeira." 24

Entretanto, problemas persistiam. Um deles, especialmente importante, dizia respeito à disparidade de requisitos de ingresso nas escolas nos diversos países, mesmo entre as escolas profissionais, ou seja, aquelas que ofereciam três anos de formação. Na Argentina, requeria-se seis anos de estudo como pré-requisito, enquanto no Chile, 12 anos eram necessários, ficando o Brasil com uma posição intermediária com nove anos de estudos como pré-requisito de ingresso. Entre as sugestões do relatório de 1952, ressaltamos aquela que recomenda que se elevem os requisitos de admissão, no sentido de exigir curso secundário completo para as candidatas às escolas de enfermagem. Esta exigência, entretanto, como veremos adiante, foi um grande empecilho na ampliação de candidatas à carreira no Brasil.

Além das avaliações, a Divisão de Enfermagem também promoveu a organização de cinco congressos regionais entre 1949 e 1959. Estes encontros 
eram momentos para a reflexão sobre a profissão, seus problemas e propostas, além de instrumento para a organização corporativa. Também foram espaços de sociabilidade e de trocas, bem como de oportunidades para formação de vínculos profissionais e pessoais. Os dois primeiros congressos, realizados em 1949, são de fundamental importância porque se tornaram referência para uma agenda de educação e organização da enfermagem no Brasil e na América Latina, com desdobramentos na década subseqüente. O protagonismo da Oficina ficou evidente na organização e financiamento dos encontros e também no empenho do diretor, Fred Soper, para que os governos nacionais se comprometessem com os congressos. ${ }^{25}$

$\mathrm{Na}$ agenda dos dois primeiros congressos destacam-se três temas: ensino profissional, condições de trabalho e organização corporativa, sendo o ensino o tema que mais mereceu deliberações. Entre as recomendações relativas ao ensino, destacam-se: que as escolas de enfermagem fossem dirigidas por enfermeiras qualificadas; que fossem instituições independentes, com orçamento próprio; que se ampliassem o número de alunas com educação secundária completa; que fosse adotado o padrão educacional mínimo recomendado pelo CIE; e que um conselho nacional de educação em enfermagem fosse organizado em cada país. Conclui-se que a agenda estava centrada na educação de nível superior, na formação de lideranças e na profissionalização. ${ }^{26}$

O que se observa neste período é a grande preocupação com a construção do próprio conceito de 'enfermeira'. As lideranças estavam preocupadas com a profissionalização da enfermagem. Isto implicava em distinguir as 'enfermeiras', ou seja, aquelas formadas por uma escola profissional, da grande massa de mulheres que desempenhavam o papel de cuidar, mas não possuíam a educação escolar recomendada pelo CIE e perseguida pela Divisão de Enfermagem. Daí a recorrência da exigência de segundo grau completo como o requisito de admissão às escolas, com os currículos referendados pelo CIE, e com o prazo mínimo de três anos de duração dos cursos. Estas condições eram imprescindíveis para que uma escola fosse reconhecida como 'profissional', ou seja, de nível universitário e padrão internacional. ${ }^{27}$

As recomendações dos congressos organizados pela Oficina coincidiam com os interesses das porta-vozes da enfermagem brasileira, organizadas na Associação Brasileira de Enfermeiras Diplomadas (ABED). A elevação do curso de enfermagem ao nível universitário é um dos assuntos mais freqüentes 
nos editoriais da Revista Brasileira de Enfermagem, que defendia esta posição como "uma das nossas maiores aspirações." Especialmente na primeira metade da década de 1950, encontramos nos editoriais deste periódico uma defesa intransigente deste tema. Para as enfermeiras brasileiras esta aspiração significava prestígio social e melhores salários, facilitando o caminho para a profissionalização. Em 1951, a ABED, elegeu, entre seus objetivos, distinguir a enfermagem como profissão de nível universitário, pois com isto seria possível conseguir a "definitiva classificação profissional que procuramos alcançar juntamente com engenheiros, médicos e arquitetos." Segundo as lideranças, no Brasil "a profissão é muito nova e a enfermeira diplomada ainda não possui, entre nós, o status social de suas colegas americanas e canadenses." ${ }^{28}$

No Segundo Congresso Nacional de Enfermeiras, ocorrido no Rio de Janeiro em 1948, a comissão organizadora adotou o seguinte lema: "Aumentar o número de enfermeiras diplomadas é cooperar no movimento mundial de saúde." As delegadas enfatizaram ser "urgente e inadiável a ampliação da capacidade de formação de enfermeiras diplomadas no país" e apelaram, ao presidente da República e ao Ministro da Educação, para que se empenhassem na "regulamentação da profissão de enfermeira e [seu] reconhecimento pelo Ministério do Trabalho." 29

Refletindo os interesses das enfermeiras diplomadas brasileiras e as recomendações da Oficina, a lei federal 775, de 1949, estabeleceu que, a partir de 1956, o curso secundário completo seria obrigatório para o ingresso em uma escola profissional de enfermagem no Brasil. A lei concedia um prazo de sete anos para que esta exigência fosse cumprida, podendo as escolas, nesta fase de transição, aceitar candidatas com o nível ginasial, desde que fossem aprovadas em processo seletivo. Esta mesma lei, entretanto, regulamentou também o curso de auxiliar de enfermagem, com dezoito meses de duração e com exigência de curso primário para ingresso. $O$ objetivo era acelerar a formação de pessoal de nível básico, diminuindo a imensa carência de pessoal minimamente qualificado para as tarefas hospitalares do cuidado com pacientes. Para garantir o controle das enfermeiras sobre a formação das auxiliares, a lei estabeleceu que "o curso de auxiliares de enfermagem será ministrado unicamente por enfermeiras diplomadas e em escolas oficialmente reconhecidas." ${ }^{30}$

Entretanto, a exigência de curso secundário completo como requisito de admissão às escolas profissionais de enfermeiras vai esbarrar em limites 
sócio-culturais, pois, no Brasil, era muito pequeno o número de mulheres jovens, de classe média, com educação secundária completa que pudessem aspirar à profissão. Na Escola de Enfermagem do Estado do Rio de Janeiro, em Niterói, que desde sua criação em 1944 já exigia o diploma do curso secundário como requisito, a diretora não conseguiu matricular uma só estudante na seleção de candidatas para o segundo semestre de 1945 - todas as aspirantes foram rejeitadas por não terem o segundo grau completo. No início de 1946, na mesma escola, inscreveram-se 25 candidatas e foram aceitas apenas 14, enquanto no segundo semestre nenhuma candidata foi considerada apta para ingressar. No segundo semestre de 1947 apenas nove estudantes foram admitidas na escola de Niterói. O problema era recorrente, pois, em 1948, candidataram-se 32 jovens para o primeiro semestre letivo, mas apenas dezoito preencheram os requisitos de ingresso. ${ }^{31}$

Esta dificuldade refletiu-se na organização nacional das enfermeiras. A ABED defendeu, a princípio, a lei 775; porém, em 1956, já transformada em Associação Brasileira de Enfermagem (ABEN), refez sua posição. Passou a reivindicar, junto ao Congresso Nacional, uma emenda à lei autorizando as escolas profissionais a matricular alunas com apenas o curso ginasial, desde que aprovadas em exame de seleção. Justificou-se tal posicionamento, com a afirmativa de que: "se a enfermagem fizer exigência de curso secundário, deverá se contentar com cerca de 200 a 300 candidatas por ano no país; se não o fizer, o número de candidatas será de dois mil." ${ }^{32}$ Observe-se que a ABEN, como um órgão que pretendia representar a Enfermagem como profissão e não apenas as enfermeiras diplomadas, supostamente tinha uma agenda mais ampla que a ABED, que falava em nome da elite da profissão.

Portanto, havia um dilema entre a proposta de um ensino superior de padrão internacional, e com base no currículo do CIE, encaminhado pela Divisão de Enfermagem da Oficina em seu programa, e o pequeno número de candidatas no Brasil que poderiam preencher estes requisitos. A exigência de segundo grau completo para ingresso nas escolas limitava de forma tão drástica o número de candidatas a enfermeiras no país, que comprometia outro objetivo do programa, que era ampliar o número destas profissionais.

Outro empecilho para a profissionalização da carreira no Brasil devia-se a uma questão de gênero: a percepção de que a enfermagem era uma profissão 'essencialmente feminina'. A carreira, segundo muitos manuais das próprias 
escolas de enfermagem, "não se adequava aos homens", porém às mulheres "por seu temperamento e caráter." ${ }^{33}$ Uma das lideranças da profissão no Brasil, Maria Rosa Pinheiro, foi muito objetiva ao apontar, em 1956, que o dilema da enfermagem no país era "um problema social", pois na medida em que exigia o "trabalho das mãos," não era considerada "uma profissão nobre, a não ser para religiosas." Segundo Pinheiro, poucas jovens de classe média "a ela acorrem e, as que a fazem, sofrem em geral, resistência da família." Pinheiro denunciava que a "posição da mulher na sociedade" influía para este conceito negativo, pois "a mulher brasileira não conseguiu ainda emancipar-se da tutela masculina" e, "contando a enfermagem com um número muito restrito de homens nas suas fileiras, custa-lhe abrir caminho numa sociedade inteiramente controlada pelos homens." ${ }^{34}$

A contradição entre o padrão de formação de enfermeiras profissionais proposto pela Divisão de Enfermagem da Oficina e as realidades locais dos diferentes países foi discutida nos congressos regionais. Já no congresso de 1953, realizado no Brasil, uma deliberação indicava que "a primeira medida a adotar para considerar os problemas da enfermagem é a necessidade de estudar a realidade local." ${ }^{35}$ Esta deliberação foi reapresentada nos congressos de 1956 (no México) e 1959 (na Argentina), demonstrando a consciência crescente da impossibilidade de importar um modelo internacional de formação de enfermeiras. A própria Organização Mundial de Saúde reconheceu, em 1953, que 'não era possível determinar um modelo inflexível' de escola e que o currículo de cada uma deveria se adaptar ao seu ambiente social, sendo o currículo do Conselho Internacional de Enfermeiras "um guia, não um modelo." 36

A partir desta deliberação, a Associação Brasileira de Enfermagem realizou, entre 1956 e 1958, uma pesquisa nacional sobre enfermagem no Brasil. O Levantamento de Necessidades e Recursos de Enfermagem contou com recursos e assessoria da Divisão de Enfermagem da Oficina e da Organização Mundial de Saúde, além de uma subvenção da Fundação Rockfeller. Também contribuíram com assessoria o Serviço Nacional de Estatística, sete ministérios e outras instituições como o SESP. Uma Oficina do Censo foi instalada em uma sala da Fundação Rockefeller, no centro do Rio de Janeiro, para centralizar o trabalho de avaliação das 32 escolas de enfermagem profissional, dos 50 cursos de auxiliares de enfermagem existentes no país; e os serviços nos hospitais e unidades sanitárias. Tratou-se de um grande mapeamento da 
enfermagem no Brasil que permitiria melhores instrumentos para a "luta das enfermeiras para melhorar a profissão no país." ${ }^{37}$

Outro desdobramento deste processo foi a reforma proposta pelo projeto de lei no. 3082, de 1957. Esta "lei orgânica de reforma do ensino de enfermagem" pretendeu uma solução para o dilema da exigência de segundo grau completo para ingresso nas escolas de enfermagem. A reforma propôs três níveis de formação. O primeiro, de nível superior, exigia o segundo grau completo para o ingresso nas escolas e conferia o grau de Licenciado em Enfermagem. Para estes, reservavam-se os cargos de professores nos cursos profissionais de enfermagem, e de direção nas escolas e nos serviços hospitalares. O segundo nível era um curso de formação de três anos, aceitando candidatos com o curso ginasial e conferindo ao diplomado o título de Enfermeiro. O terceiro curso, já regulamentado pela lei 775, era o de auxiliar de enfermagem, ministrado em 18 meses. ${ }^{38}$ Segundo a Associação Brasileira de Enfermagem, esta reforma permitiria "maior afluxo de candidatos à profissão", maior facilidade para as escolas traçarem seus objetivos e elaborarem currículos, bem como instalaria uma definição clara de hierarquia e estratificação salarial, permitindo "salários justos, uma vez que [...] a classe obterá a mesma estratificação existente em outras profissões: o auxiliar, o técnico e o profissional técnico-científico." 39

Ou seja, diante das diferenças sociais e culturais, o modelo de uma enfermagem inspirada nos padrões anglo-saxões do CIE teve que adaptar-se à realidade brasileira, onde limitações de classe, cultura e gênero impediam o acesso de um grande número de mulheres às escolas idealizadas pelo programa da Oficina. A proposta de reforma da enfermagem brasileira pela Lei 3082 foi a resposta que a realidade local forneceu ao dilema. Ao criar três níveis de formação, procurou-se equacionar o problema de acesso às escolas, ao mesmo tempo em que se hierarquizava a profissão e regulamentava a situação da grande maioria das trabalhadoras ou trabalhadores que praticavam a arte de cuidar, porém não tinham treinamento ou educação escolar especializada.

A transformação da ABED em ABEN em 1954 é muito sintomática: a nova associação não pretendeu ser apenas das 'enfermeiras diplomadas', ou seja, da elite da profissão, mas sim da 'enfermagem', com toda a complexidade e diversidade que o termo significava. Apesar de a ABEN continuar privilegiando a formação das enfermeiras, ou seja, das profissionais de nível superior, a Associação reconhecia que havia grande necessidade das "auxiliares"

\section{Maracanan}


em virtude da escassez das "profissionais" e aceitava a formação das auxiliares, desde que, sob supervisão das enfermeiras.

\section{A REORIENTAÇÃO DO PROGRAMA: DE ENFERMEIRAS PROFISSIONAIS PARA AUXILIARES DE ENFERMAGEM}

O tema das 'auxiliares de enfermagem' ecoou no congresso regional de 1956, determinando, no limite, que a Oficina reorientasse sua atuação. Naquela ocasião, as delegadas reconheceram que era preciso tratar da formação do pessoal auxiliar, naturalmente, sob o controle das enfermeiras profissionais. O congresso recomendou então, que o ensino para a formação de auxiliares fosse regulado nos países; que o número de auxiliares fosse limitado a partir de uma relação percentual com o número de enfermeiras profissionais; e que se estabelecesse uma clara distinção entre 'enfermeiras' e 'auxiliares', sendo que estas não poderiam denominar-se 'enfermeiras', devendo usar "outro uniforme" como forma de distinção. ${ }^{40}$

A partir de meados da década de 1950, com o reconhecimento de que cada país estudasse as condições locais da enfermagem e, com a recomendação nos congressos regionais sobre a necessidade de regular a função de 'enfermeira auxiliar', a Divisão de Enfermagem da Oficina reorientou seu objetivo. Do foco inicial, voltado para o ensino superior e formação de lideranças, passou-se a privilegiar o "adestramento de pessoal empírico, suprindo suas carências de formação e "colocando-as sob supervisão profissional." ${ }^{41}$ Para isto, sugeriu-se que a formação de uma auxiliar de enfermagem deveria se estender a um período entre 6 e 18 meses, sendo que os requisitos de admissão deveriam "variar entre o curso primário completo a três anos de educação secundária, naqueles países onde a educação da mulher é mais comum." ${ }^{\prime 4}$

A mudança de foco do programa foi sinalizada no congresso regional de 1959, na Argentina, quando Agnes Chagas, assessora da Divisão da Enfermagem, oficializou a retirada da Oficina, a partir de 1962, da organização dos congressos regionais, delegando esta responsabilidade para as associações de enfermeiras locais. A iniciativa foi considerada "um novo capítulo da história da enfermagem na América Latina", significando que a enfermagem profissional já havia adquirido maturidade suficiente para organizar, com 
autonomia, sua agenda. Chagas informou, entretanto, que a Oficina não abandonaria completamente a enfermagem profissional, pois os "assessores de enfermagem [da Oficina] continuarão colaborando [com as associações profissionais] quando solicitados. ${ }^{, 43}$

Assim, a formação de nível superior deixou de ser, a partir de 1959, o foco da Divisão de Enfermagem da Oficina Sanitária-Panamericana. Na década seguinte, a Oficina passou a privilegiar a formação de recursos humanos de nível básico. Esta nova orientação refletia também a transformação que representou a gestão do médico chileno Abraham Horwitz (1958-1975), que substituiu Fred Soper na direção da OPAS. Na administração de Horwitz, a afirmação da "saúde como direito de todos", privilegiou a reforma do ensino médico e a qualificação de um grande número daqueles genericamente designados como "trabalhadores auxiliares da saúde," onde se inclui o/a auxiliar de enfermagem. Se durante a direção de Soper, o objetivo da Divisão de Enfermagem era modernizar o ensino superior e ampliar o número de escolas profissionais de enfermagem, na administração Horwitz, o "direito à saúde" significou a preocupação do treinamento de pessoal básico. De acordo com esta nova postura, no início da década de 1970, um acordo entre a OPAS e o governo brasileiro, criou o Programa de Preparação Estratégica de Pessoal de Saúde, que tinha como primeiro objetivo, "promover a formação em massa de pessoal técnico e auxiliar" de saúde, entre eles, os trabalhadores da enfermagem. ${ }^{44}$ 


\section{Notas e Referências}

1 Paul WEINDLING. "Constructing international health between the wars". In: International Health: organizations and movements, 1918-1919. In: Paul Weindling (Ed). Cambridge: Cambridge University Press, 1995, p. 1-13.

2 Esta pesquisa contou com a valiosa colaboração do bolsista de Iniciação Científica, Wesley Rodrigues de Carvalho

3 Martin D DUBLIN. "The League of Nations Health Organization.” In: Paul Weindling (Ed). Opus cit, p.56-80; BIRN, Anne-Emmanuelle. Marriage of Convenience. Rockefeller International Health and Revolutionary Mexico. Rochester, NY: University of Rochester Press, 2006, p. 262-67.

4 Para a Fundação Rockefeller ver: Luiz Antonio CASTRO SANTOS \& Lina Rodrigues FARIA. "A cooperação internacional em enfermagem de saúde pública no Rio de Janeiro e São Paulo.” Horizontes, vol. 22, nº. 2, Bragança Paulista, SP (2004): 123-150; para o IAIA e o SESP ver: André Luiz Vieira de CAMPOS. Políticas Internacionais de Saúde na Era Vargas: o Serviço Especial de Saúde Pública, 1942-1960. Rio de Janeiro: Ed. Fiocruz, 2006, p. 33-65.

5 O Conselho Internacional de Enfermeiras é uma organização fundada em Londres, em 1899, cuja agenda inclui a organização profissional das enfermeiras e o controle do padrão de qualidade do ensino e serviços daquelas profissionais. O CIE reconhecia como "escolas profissionais" de enfermagem, apenas aquelas de nível universitário e que se adequassem aos seus métodos e padrões de ensino. Com a Segunda Guerra, a importância política do CIE deslocou-se para os EUA, o que vai favorecer a influência da enfermagem norte-americana no Brasil. Cf: Bárbara L. BRUSH \& Joan E. LYNAUGHT (eds). Nurses of All Nations: A history of the International Council of Nurses, 1899-1999. Philadelphia, PA: Lippicott Williams \& Wilkins, 1999.

6 Desde 1923 a Oficina Sanitária publica, regularmente, o Boletim da Oficina Sanitária Panamericana, que manteve seu nome mesmo após a reforma daquela agência em 1947.

7 Além da criação de escolas profissionais, o Boletim registra outros dados como: número de enfermeiras diplomadas, suas condições de trabalho, legislação sobre o ensino e carreira, história da profissão, além de um reclamo constante sobre o pequeno número de profissionais nas Américas. 
8 Além da FR e do IAIA, também a Fundação Kellog, a Cruz Vermelha Internacional e o Conselho Internacional de Enfermeiras atuavam na cooperação em enfermagem no Brasil.

9 André Luiz Vieira CAMPOS. Op. cit, p. 221-251.

10 Cristina M. Oliveira FONSECA. Saúde no governo Vargas (1930-1945): dualidade institucional de um bem público. Rio de Janeiro: Ed. Fiocruz, 2007; Gilberto HOCHMAN \&, Cristina M. O FONSECA. "I Conferência Nacional de Saúde: reformas, políticas e saúde pública em debate no Estado Novo.” In: Ângela M. de Castro GOMES (org.). Capanema: o ministro e seu ministério. Rio de Janeiro/Bragança Paulista: Ed. FGV, 2001, p. 173-193; André Luiz Vieira de CAMPOS. Opus cit.

11 Cristina M. O FONSECA. Op. cit, p. 175-183.

12 Nísia Trindade LIMA. "O Brasil e a Organização Pan-Americana de Saúde: uma história em três tempos." In: Jacobo FINKELMAN. (org.) Caminhos da Saúde Pública no Brasil. Rio de Janeiro: Ed. Fiocruz, 2002, p. 23-106.

13 Miguel E BUSTAMANTE. "Os 50 primeiros anos da Oficina Sanitária Pan-americana”. In: BOSP. vol. 31, nº 12 (1952): 501-506.

14 Pan American Sanitary Bureau. Annual Report of the Director, Fiscal year 19411942. Publication no 194. Washington, DC: PASB, 1942, p.22.

15 Relatório do IAIA citado por André Luiz Vieira de CAMPOS. Opus cit. p. 225.

16 "Nova seção Enfermagem no Boletim da Oficina Sanitária Pan-americana." In: BOSP. vol. 22, $\mathrm{n}^{\circ} .4$ (1943): 355-56. Apesar de anunciada em 1943, a seção Enfermagem apenas se consolidou em 1949, o que nos sugere que, só com a reorganização da Oficina em 1947, sob a direção de Fred Soper, houve recursos e estrutura material para o programa de enfermagem.

17 “I Congresso Pan-americano de Enfermagem, Santiago, Chile." In:BOSP. vol. $22, n^{\circ} .4$ (1943): 358.

18 Citado por Aline Maria SOUZA. Desenvolvimento dos serviços de assessoria de enfermagem da Organização Pan-americana de Saúde: Impacto na educação de enfermagem latino-americana (1940-1980). Tese de doutorado, Ohio State University, 1982, p. 126.

19 Pan American Sanitary Organization. Official Document. No 11, July 1955. Annual Report of the Director of the Pan American Sanitary Bureau, Regional Office for the Americas of the WHO. 1954. Washington, DC: Paho, July, 1955, p.1 
20 Fred SOPER. "Celebracion del dia Panamericano de la salud em Washington, D.C." In: BOSP, (fevereiro, 1949): 160-61.

21 “Enfermeria." In: BOSP, (fevereiro, 1950): 199.

22 "Enfermeria." In: BOSP, vol. 27, nº 10 (1948): 960-963. O padrão Nigthingale refere-se aos requisitos, métodos e procedimentos de ensino e de serviços de enfermagem criados a partir do trabalho da britânica Florence Nightingale (1820-1910). Nightingale foi enfermeira voluntária na guerra da Criméia e, ao voltar à Inglaterra fundou, em 1859, a primeira escola laica e moderna de enfermagem naquele país. O padrão Nightingale de enfermagem foi difundido universalmente a partir de 1899, graças à ação do Conselho Internacional de Enfermeiras.

23 Agnes W. CHAGAS. "Observaciones preliminares sobre las escuelas de enfermeria em la América Latina.” In: BOSP. 2 (1950): 200. Além destas cinco escolas brasileiras, receberam classificação mais alta três escolas do Chile. Colômbia, Equador, Haiti, Peru e Venezuela contaram, cada um,com uma escola classificada na categoria mais alta.

24 Agnes W CHAGAS. "La educación de enfermeras em la America Latina." In: BOSP, (janeiro, 1952): 48.

25 O primeiro congresso, realizado na Costa Rica em 1949, reuniu enfermeiras da América do Norte e Caribe; o segundo congresso, sediado no Peru no mesmo ano, contou com representantes dos países do Sul do Continente. Os Congressos subseqüentes não tiveram esta divisão norte-sul: o terceiro aconteceu em 1953 no Brasil; o quarto em 1956, no México; o quinto em 1959 na Argentina.

26 "Summary of the First and Second Regional Nurses' Congresses." In: BOSP, (Janeiro, 1950): 105.

27 Em 1955, a Oficina estabeleceu uma distinção básica entre duas grandes categorias: a "enfermeira profissional" - com educação formal em escola reconhecida pelo Estado - e a "auxiliar de enfermagem" - de formação empírica. Logo se regularia a formação das auxiliares de enfermagem, com exigência de 18 meses de estudos, sob a supervisão das enfermeiras profissionais.

28 "Integração da enfermagem no movimento dos profissionais de nível universitário superior." In: Anais de Enfermagem, n. 3, vol. IV (1951): 209-10. Com o padrão universitário reconhecido, as enfermeiras poderiam reinvindicar a classificação "O", a mais alta da hierarquia profissional e salarial do quadro de funcionários federais. 
29 “Congresso Nacional de Enfermeiras." In: BOSP, vol. 27, nº 12 (1948): 1208-1209.

30 "Legislación sobre enfermería em el Brasil." BOSP, 6 (1951): 771. Havia uma discordância entre os sanitaristas do Departamento Nacional de Saúde (DNS) e as diretoras das escolas profissionais de enfermagem. Estas insistiam que o governo deveria privilegiar a formação de enfermeiras de nível superior, enquanto aqueles defendiam a formação de pessoal de nível básico como forma de suprir a carência de enfermeiras no Brasil. Cf: Wellington M. AMORIM \& Ieda de Alencar BARREIA. "A missão de Maria de Castro Pamphiro na primeira escola de enfermagem brasileira, 1937-1949.” In: Fernando PORTO \& Wellington AMORIM. História da enfermagem brasileira: lutas, ritos e emblemas. Rio de Janeiro: Águia Dourada, 2007, p. 285-88

31 André Luiz Vieira de CAMPOS. Opus cit. p. 226-28.

32 "Reforma do ensino de enfermagem," Revista Brasileira de Enfermagem, n'. 3, vol. IX, (1958): 183-5. A lei 775 foi modificada em 1957, postergando a exigência de segundo grau completo para 1961.

33 Manual da Escola de Enfermagem de São Paulo, Citado por CAMPOS, André Luiz Vieira de. Obra citada, p. 228.

34 Maria Rosa de Sousa PINHEIRO. "Razões para a realização de um inquérito de recursos e necessidades de enfermagem." In: BOSP, ano 38, vol. XLVI, nº 5 (1959): 407-411. Maria Rosa de Souza Pinheiro foi Diretora da Escola de Enfermagem da Universidade de São Paulo e Presidente da Associação Brasileira de Enfermagem.

35 Agnes W. CHAGAS. "Informe sobre los Tercero, Cuarto y Quinto Congressos Regionales de Enfermeria." In: BOSP, vol. 40, n. 5, Washington, DC (1961): 435-440.

36 CREELMAN, Lyle. "Relação entre a Organização Mundial de Saúde e a Enfermagem Profissional." BOSP, 32, XXXV, no. 3 (1953): 244.

37 "Qualidade e quantidade na enfermagem." In: Revista Brasileira de Enfermagem, $n^{\circ}$ 1, vol. IX (1956): 4.

38 "Reforma do ensino de enfermagem." In: Revista Brasileira de Enfermagem, no. 3, vol.IX, (1958): 183-5.

39 “Editorial”. In: Revista Brasileira de Enfermagem, n. 2, vol. X (1957): 105-6

40 Agnes W CHAGAS. "Informe sobre los Tercero, Quarto y Quinto Congressos Regionales de Enfermería," In: BOSP, n 40, vol. 5 (1961): 439. 
41 Agnes W CHAGAS. "Informe sobre los Tercero, Quarto y Quinto Congressos Regionales de Enfermería.” In: BOSP, nº 40, vol. 5 (1961): 438.

42 Hilda LOZIER. "Definiciones de los nombres y de las funciones del pessoal de enfermería." In: BOSP, ano 34, XXXIX, no 3 (1955): 223.

43 Agnes W CHAGAS. "Informe sobre los Tercero, Quarto y Quinto Congressos Regionales de Enfermería.” In: BOSP. no. 40, vol. 5. (1961): 438.

44 Fernando PIRES-ALVES \& Carlos H. Assunção PAIVA. Recursos críticos: história da cooperação técnica Opas-Brasil em recursos humanos para a saúde (19751988). Rio de Janeiro: Ed. Fiocruz, 2006, p.9-16. 